\title{
El sustrato cientificista de la antropología estructural: una crítica desde la hermenéutica (segunda parte). Lévi-Strauss y la interpretación del mito: las incongruencias del método
}

\author{
The Cientificist Substratum of Structural Anthropology: \\ A Criticism through Hermeneutics (second part). Lévi-Strauss \\ and the Interpretation of Myth: The Incongruence of the Method
}

\author{
Julio Alberto Amador Bech \\ Universidad Nacional Autónoma de México
}

\begin{abstract}
RESUMEN: El presente artículo se propone llevar a cabo una crítica sistemática de los presupuestos teóricos que subyacen a la antropología estructural de Claude Lévi-Strauss. Para tal fin se parte de una reconstrucción hermenéutica de sus principales planteamientos, a partir de su obra Antropología estructural, en particular su proposición de tomar a la lingüística estructural y, dentro de ésta, a la fonología de Trubetzkoy, como modelo de cientificidad para la antropología. Se trata de mostrar que a pesar de que tal modelo parece provenir de las ciencias sociales, en realidad el concepto de cientificidad que rige el estructuralismo de Lévi-Strauss no es el de la lingüística, sino el de las ciencias naturales y que, en ese sentido, su pensamiento es afín al positivismo y al cartesianismo. En consecuencia, propongo que la perspectiva hermenéutica desde la cual se debe abordar el estudio del mito, en particular, y de la problemática de la etnografía, en general, no es la del estructuralismo de Lévi-Strauss, sino que el proceso de comprensión debe realizarse de modo que no se violente la especificidad cultural y el ser humano vivo vuelva a estar en el centro de la antropología.
\end{abstract}

ABSTRACT: The present article intends to accomplish a systematic critique of the theoretical basis that underlies Claude Lévi-Strauss's structural anthropology. With that in mind, we begin with a hermeneutics reconstruction of its main propositions, starting from the basic ideas presented in his work Structural Anthropology, in particular, his suggestion concerning the idea of using structural linguistics, and especially, Trubetzkoy's phonology, as a scientific model for anthropology. I try to demonstrate that, even though that model seems to come from the social sciences, actually, the concept of scientific rigor that rules Lévi-Strauss's structuralism comes from the natural sciences, and, in that sense, his thought is akin to Positivism and Cartesianism. In consequence, I propose that the hermeneutic perspective from which, particularly, the study of myth should be dealt with and, in general, the question of ethnography, is not that of Lévi-Strauss's structuralism. The process of comprehension should occur in another way, so that the specific cultural traits of the human groups that are studied and the living human being will return to the center of anthropological thought.

Palabras ClaVE: cientificismo, antropología estructural, hermenéutica, interpretación del mito.

KEYWORDS: scientism, structural anthropology, hermeneutics, myth interpretation.

RECIBIDO: 23 de marzo de 2017 • ACEPTADO: 25 de agosto de 2017

Interpretatio, 3.1, 2018, pp. 163-190 



\section{Julio Alberto Amador Bech}

Universidad Nacional Autónoma de México

\section{El sustrato cientificista de la antropología estructural: una crítica desde la hermenéutica (segunda parte). Lévi-Strauss y la interpretación del mito: las incongruencias del método ${ }^{1}$}

\section{Introducción}

Una vez que he mostrado el trasfondo cientificista y metafísico de la teoría antropológica de Lévi-Strauss, puedo abordar los problemas que plantea su método estructural en el análisis de textos y, en particular, en el análisis de los mitos. En la interpretación del mito que encontramos en la Antropología estructural de Lévi-Strauss, nos topamos con un procedimiento semejante al utilizado para estudiar las relaciones de parentesco; el modelo estructuralista deriva, explícitamente, de la lingüística estructural de Saussure (Lévi-Strauss 1970: 186-210). Se trata de un análisis exclusivamente semiótico, en el sentido de que se estudia al mito como un sistema cerrado de signos, totalmente independiente de la tradición cultural concreta de la cual surgió, totalmente independiente de los usos, significados y funciones que al interior de ella se produjeron. De nuevo, el ser humano vivo, centro y fundamento de la antropología, está ausente, sólo subsiste el cascarón del sistema, la estructura vacía a la cual se pretenderá hacer hablar por la aplicación de

Para la primera parte del presente artículo, véase Interpretatio. Revista de Hermenéutica, vol. 2, núm. 1, marzo-agosto 2017, pp. 155-194 (nota de los editores). 
un método que tiene tanto de arbitrario como de apriorístico y al cual debemos culpar por la inconsistencia de las conclusiones a las cuales se llega.

Las distinciones saussureianas entre lengua y habla sirven a LéviStrauss para diferenciar, al interior del mito, entre una "estructura permanente", situada fuera del tiempo, en una dimensión sincrónica - equivalente a la que la lengua tiene en el Curso de Saussure-, y un "sistema temporal" - pues "[un] mito se refiere a acontecimientos pasados"-, el cual correspondería al del habla (Lévi-Strauss 1970: 189). Desde esta perspectiva, Lévi-Strauss emprende su análisis: “Esta doble estructura, a la vez 'histórica' y 'ahistórica', explica que el mito pueda pertenecer simultáneamente al dominio del habla (y ser analizado en cuanto tal) y al de la 'lengua' (en la cual se lo formula), ofreciendo al mismo tiempo, en un tercer nivel, el mismo carácter de objeto absoluto. Este tercer nivel posee también una naturaleza lingüística, pero es, sin embargo, distinto de los otros dos" (Lévi-Strauss 1970: 189-190).

A partir de aquí, afirma que el sentido de los mitos no puede depender de los elementos aislados que lo componen, sino de la manera en la cual se combinan. Luego, el mito pertenece al orden del lenguaje, del cual es una manifestación específica y, por último, estas propiedades van más allá de la expresión linguística común, son de naturaleza más compleja, por lo cual exigen ser comprendidas en un nivel más alto. Hasta aquí, pueden aceptarse los supuestos básicos de los que parte, especialmente los últimos, que son comunes a la semiología francesa y a la hermenéutica fenomenológica y que son compartidos por autores como Roland Barthes y Paul Ricoeur.

En su estudio sobre las mitologías modernas, Barthes explicita una doble estructura significante, propia del mito; lo concibe como un sistema semiológico segundo (Barthes 1980 [1957]: 205-206). Tenemos, desde su punto de vista, dos planos diferentes de significado del mito. El primero sería el del lenguaje objeto, que podemos identificar con el plano literal, correspondiente a la historia o suceso narrado: el acontecimiento en sí mismo. En este plano nos limitamos a la simple narración de la historia, nos ceñimos a los hechos relatados, por extraordinarios que éstos puedan parecer. 
Pero en el mito, como en la imagen poética o pictórica, el plano literal es sólo una figura metafórica que sirve de medio para transmitir un sentido o conocimiento "oculto", un segundo plano de significado, el que él llama metalenguaje. Es decir, el mito posee un sentido implícito diferente del sentido explícito, presente en su literalidad. El segundo sentido (metalenguaje), que podemos entender como plano conceptual, por oposición al primero, revela su sentido profundo. Se aborda, así, al mito, ya sea en su forma de texto o de imagen, en tanto estructura significativa que requiere ser interpretada.

Por su parte, Ricoeur muestra esta distinción de niveles significantes como el nudo semántico de toda hermenéutica. De la exégesis al psicoanálisis, el elemento común es una cierta arquitectura del sentido que propone un "doble significado" o un "múltiple significado" (Ricoeur 2003: 17). De tal suerte, Ricoeur define a la interpretación como el trabajo del pensamiento que consiste en "descifrar el significado oculto en el significado aparente", desenvolviendo sus niveles, implicados en el plano literal (Ricoeur 2003: 17). Si, a la manera de Ricoeur, se entiende al símbolo como una expresión polisémica y existencialmente caracterizada, la mera decodificación epistémica sería insuficiente, exigiéndose, así, una aproximación hermenéutica, es decir, ontológica; más aún, la hermenéutica encuentra su razón de ser en la interpretación de los símbolos:

Llamo símbolo a toda estructura de significación donde un sentido directo, primario y literal, designa por añadidura otro sentido, indirecto, secundario y figurado, que sólo puede ser aprendido a través del primero. Esta circunspección de las expresiones de doble sentido constituye propiamente el campo hermenéutico [...] la interpretación es el trabajo del pensamiento que consiste en descifrar el sentido oculto en el sentido aparente, en desplegar los niveles de significación implicados en la significación literal [...] Símbolo e interpretación se convierten en conceptos relativos. Hay interpretación allí donde hay sentido múltiple, y es en la interpretación donde la pluralidad de sentidos se pone de manifiesto (Ricoeur 2003: 17; cursivas en el original).

En años posteriores (1976) Ricoeur matizó su posición al respecto, ampliando el ámbito de la hermenéutica, para abarcar "el problema completo del discurso": 
Hace algunos años yo solía relacionar la tarea de la hermenéutica principalmente con el desciframiento de las diversas capas de sentido del lenguaje simbólico y metafórico. Sin embargo, en la actualidad pienso que el lenguaje simbólico y metafórico no es paradigmático para una teoría general de la hermenéutica. Esta teoría debe abarcar el problema completo del discurso, incluyendo la escritura y la composición literaria. Pero aún en este planteamiento se puede decir que la teoría de la metáfora y de las expresiones simbólicas permite que se prolongue decisivamente el campo de las expresiones significativas, al agregar la problemática del sentido múltiple al del sentido general (Ricoeur 2006: 90).

Hasta aquí podemos decir que existen algunas coincidencias entre estos autores; sin embargo, queda muy claro que la hermenéutica de Ricoeur, a diferencia del estructuralismo de Lévi-Strauss, propone una interpretación que va más allá del mero nivel semiótico, del puro análisis del texto en sí mismo, entendido como conjunto de relaciones lógicas que constituyen un sistema cerrado. Ricoeur propone, además, un nivel semántico de interpretación que permite relacionar el sistema de signos estudiado, con el mundo que esos signos refieren, y un nivel histórico-cultural y práctico que sitúa al sistema de signos en el proceso vivo del uso y la interpretación en el campo de la experiencia humana. Así, en su Introducción al primer volumen de Tiempo y narración señala que "el problema epistemológico planteado, tanto por la metáfora como por la narración, consiste en relacionar la explicación, propia de las ciencias semiolingüísticas, con la comprensión previa que deriva de la familiaridad adquirida con la práctica del lenguaje, tanto poético, como narrativo" (Ricoeur 2007 [1985]: 32-33).

Ricoeur ya había mostrado con toda claridad que los análisis lingüísticos que tratan a la estructura semántica de la expresión como algo cerrado sobre sí mismo, de manera ineluctable convierten al lenguaje en un absoluto. La hipóstasis del lenguaje opera de tal forma que oculta que el signo, en realidad, está en lugar de, ocupa el lugar de algo, propio de la existencia, pues el lenguaje es una construcción significante que debe ser referida a la existencia (Ricoeur 2003: 20).

Franz K. Mayr define claramente la diferencia de orientación entre los estructuralismos y la hermenéutica: 
En la tradición hermenéutica, el lenguaje no se entiende primariamente como sistema de signos objetivable y susceptible de formalización matemática, sino como lenguaje materno, vinculado al tiempo, a la situación y a la tradición, y dotado de la fuerza expresiva del lenguaje cotidiano, que encuentra su culminación en el lenguaje poético, como mensaje lingüísticamente mediado por una experiencia global del mundo, dialógica e histórica. Aquí el lenguaje se concibe partiendo del acto de habla contextual y social-histórico, desde su apertura a las variaciones de sentido, y se le concede prioridad a la "función expresiva" sobre la "función representativa" (Mayr 1994: 322-323).

\section{Lévi-Strauss y la interpretación estructural del mito}

Siguiendo el método estructural de Lévi-Strauss, el "significado profundo" del mito se obtiene descomponiéndolo en fragmentos (mitemas), los cuales son sacados de su contexto discursivo (campo semántico) - ahí donde adquirirían sentido, a partir de la continuidad diacrónica de la narración - y son ordenados a partir de oposiciones "binarias" (positivas o negativas) en un plano sincrónico, basado por completo en la lógica formal, propia de la filosofía analítica moderna. ${ }^{2}$ El plano sincrónico se contrasta con el diacrónico, pero, en realidad, en el plano que Lévi-Strauss llama diacrónico, dentro de su modelo, no nos topamos con una verdadera sucesión diacrónica de los fragmentos del relato, lo que para Aristóteles y Ricoeur constituiría la trama del relato. Por el contrario, nos topamos con una selección arbitraria de momentos articulados temáticamente de distintos mitemas, que, en el fondo, se organizan sólo para "demostrar" la hipótesis del autor y que son seleccionados por un método de prueba y error, ya que él mismo propone que se proceda: "ensayando sucesivamente diversas disposiciones de

2 De principio, utilizar el término binario para aplicarlo al análisis de textos constituye un grave error. Los sistemas binarios pertenecen al sistema operativo de las computadoras; son un sistema matemático de oposiciones excluyentes entre los dígitos 0 y 1 , cuya aplicación al discurso humano o a los productos culturales resulta totalmente arbitrario, reductivo e incapaz de dar cuenta de la complejidad contenida en un texto, no se diga en un mito. En todo caso, al referirnos al mito y a la religión podemos hablar de dualismo o de oposiciones duales; resulta totalmente equívoco emplear el concepto binario en tales casos. 
los mitemas, hasta que se encuentre una que satisfaga las condiciones" (Lévi-Strauss 1970: 193). Se refiere a las condiciones por él propuestas: "economía de explicación, unidad de solución, posibilidad de reconstruir el conjunto a partir de un fragmento y de prever los desarrollos ulteriores a partir de los datos actuales" (Lévi-Strauss 1970: 191).

Por otra parte, su método no lleva a cabo un verdadero análisis de la dimensión del habla, como lo pretende el autor, pues el proceso vivo de uso práctico de la narración mítica - lo que sería el uso social del mito, propiamente dicho-, está ausente por completo de su análisis y sólo tenemos la ordenación diacrónica de los sucesos dentro del texto, fuera de toda práctica social y de toda historia viva. ¿Qué es el habla, sino el uso social de la lengua? El análisis de lo que él llama la dimensión del habla sólo puede lograrse cuando existe un trabajo etnográfico cuidadoso y sistemático y la gente del grupo que estudiamos nos dice, de viva voz, qué significa para ellos el mito, al interior de los múltiples momentos de la vida comunitaria. Esto no ocurre de manera sistemática en los ejemplos analizados en la Antropología estructural; no será sino hasta seis años después, cuando en Lo crudo y lo cocido, primer volumen de Mitológicas, emprenda un análisis, contextualizado a partir de algunos materiales etnográficos y etnohistóricos (Lévi-Strauss 1996 [1964]). Sin embargo, aún en ese caso, en ningún momento recoge los testimonios de los grupos estudiados, testimonios que nos darían las claves etnográficas concretas del significado de los mitos que se analizan y de sus funciones y usos dentro de la vida social.

Su modo de proceder contrasta claramente con las lúcidas enseñanzas de Malinowski, quien señalaba que el antropólogo tiene la ventaja, en relación con la interpretación del mito, de consultar a sus informantes "siempre que siente que sus doctrinas se tornan confusas y que el flujo de su elocuencia argumentativa va seco" (Malinowski 1994 [1948]: 112). A lo que agrega:

El antropólogo no está atado a los escasos restos de una cultura, como tablillas rotas, deslucidos textos o fragmentarias inscripciones. No precisa llenar inmensas lagunas con comentarios voluminosos, pero basados en conjeturas. El antropólogo tiene a mano al propio hacedor del mito. No sólo puede tomar un texto en el estado en el que existe, con todas sus variaciones, y 
revisarlo una y otra vez; también cuenta con una auténtica hueste de auténticos comentadores de los que puede informarse; y lo que es más, con la totalidad de la vida de la que ha nacido el mito. Y como veremos, hay tanto que aprender en relación al mito en tal contexto vital como en su propia narración (Malinowski 1994: 112).

Como podemos ver, las conclusiones que Malinowski desprende de su experiencia etnográfica constituyen una crítica radical del modo de proceder de Lévi-Strauss, quien dejó de lado, por completo, los más básicos principios de la etnografía.

Paul Ricoeur ya había formulado una crítica al modelo de Lévi-Strauss con un sentido semejante, cuando señala claramente que el análisis diacrónico de dicho modelo entra en crisis y es insuficiente cuando se enfrenta "a una verdadera tradición, es decir, a una serie de continuaciones interpretantes, que ya no pueden ser consideradas como la intervención del desorden en un estado del sistema" (Ricoeur 2003: 36).

El enfoque estructuralista de Lévi-Strauss parte de nociones universalistas abstractas que dejan siempre en un segundo plano, o simplemente excluyen, lo concreto y particular. Explícita e implícitamente, subsume la dimensión temporal y concreta de los procesos culturales a la estructura atemporal y abstracta; deja en suspenso el carácter activo de la relación humana con la cultura y el carácter concreto de toda construcción cultural. Así, Lévi-Strauss se equivoca al subordinar, para los fines del análisis estructural de los relatos míticos, las estructuras narrativas diacrónicas a las oposiciones lógicas "binarias", sincrónicas, pues las narrativas míticas son esencialmente plurales, dinámicas, progresivamente complejas y su sustancia es el tiempo (Ricoeur 1999, 2007).

Por el contrario, Ricoeur partirá de las hipótesis heideggerianas de Ser y tiempo para demostrar que nuestra capacidad hermenéutica de comprender toda narración radica en nuestra condición ontológica de vivir en el tiempo: "la temporalidad es una estructura de la existencia - una forma de vida - que accede al lenguaje mediante la narratividad, mientras que ésta es la estructura lingüística - el juego del lenguaje - que tiene como último referente dicha temporalidad" (Ricoeur 1999: 183).

Tal como ocurre en los sueños, los símbolos que aparecen en los mitos cambian su figura y su sentido, se transmutan constantemente, en función 
del campo semántico específico de la narración en el que se encuentren. Es precisamente esto a lo que se refiere Ricoeur cuando afirma que "un símbolo separado no tiene sentido; más aún: un símbolo separado tiene demasiado sentido" (Ricoeur 2003: 58). Concluye: "los símbolos únicamente pueden simbolizar en conjuntos que limitan y articulan sus significaciones" (Ricoeur 2003: 60). Como afirma Durand: "No es que un solo símbolo no sea significativo como todos los demás, sino que el conjunto de todos los símbolos relativos a un tema los esclarece entre sî" (Durand 1971: 17).

La interpretación de los relatos míticos requiere comprender que la dimensión temporal es su elemento sustantivo: pertenece a su estructura profunda y no a su estructura superficial (Ricoeur 1999: 108-132). Es de tal modo que se plantea la cuestión en el primer volumen de Tiempo y narración, de suerte que queda claro que la temporalidad es, a la vez, la condición ontológica del ser humano, y un modo intrínseco de comprender la vida, expresada mediante la narración, caracterizada por poseer una estructura temporal. Concluye que

[...] entre la actividad de narrar una historia y el carácter temporal de la existencia humana existe una correlación que no es puramente accidental, sino que presenta la forma de necesidad transcultural. Con otras palabras: el tiempo se hace tiempo humano en la medida en la que se articula en un modo narrativo, y la narración alcanza su plena significación cuando se convierte en una condición de la existencia temporal (Ricoeur 2007: 113).

En segundo lugar, podemos afirmar que, debido a que los temas míticos son de tal variedad y complejidad, su reducción a un repertorio limitado de funciones lógicas "binarias", tal como lo pretendió Lévi-Strauss, resulta del todo arbitraria y artificiosa: su oposición "binaria" no obedece a la lógica propia de los mitos, supone una imposición artificial externa, proviene de la informática, la cual influyó de manera muy importante en el estructuralismo, tal como el mismo Lévi-Strauss lo reconoce. Al extraer los fragmentos míticos (mitemas) de su campo semántico original, que es diacrónico, situado en la dimensión temporal, y agruparlos en secuencias lógicas "binarias", sincrónicas, se violenta la lógica argumental y el significado sustantivo de los mitos, pues se les somete a una 
lógica formal que les es del todo ajena. Mito y símbolo operan en función de sistemas de analogías o, mejor, de homologías diferenciales (Durand 1971: 1993), un modo totalmente distinto al de la lógica "binaria" de los sistemas informáticos digitales. "Reducido de esta manera el mito a un juego estructural - dirá Durand - , uno se da cuenta de que la combinatoria estructural, que en primera instancia parecía tan complicada, es muy simple, en definitiva, de una simplicidad casi algebraica [...] se convierte en un "simple instrumento lógico" (Durand 1971: 65).

El problema de fondo que plantea el método de Lévi-Strauss se pone de manifiesto en su acrítica universalización de la lógica formal, propia de la filosofía analítica occidental, por el contrario, los mitos recopilados en los cuatro volúmenes de Mitológicas obedecen a una lógica de pensamiento totalmente distinta. El asunto es particularmente grave en su caso, pues realizó un extenso trabajo de campo en sociedades de oralidad primaria y recopiló mitos que pertenecían a diversas formas de tradición oral; culturas totalmente ajenas a la escritura y a las formas de pensar que se derivan de ésta: la lógica deductiva formal-racional. Perspectiva que podemos contrastar con las de Walter Ong y Eric Havelock, quienes muestran que las sociedades de oralidad primaria se caracterizan por una forma de pensar y ser activa, concreta, contextualizada y situada en el tiempo, donde la narratividad dota de sentido a seres, cosas y acciones, pensamiento radicalmente distinto del que es propio de las sociedades basadas en la escritura y en los procesos de abstracción que le son inherentes (Havelock 1986; Ong, 2004 [1987]).

Ong, siguiendo a Goody, expresa claramente una crítica a los procedimientos analíticos utilizados, principalmente por la antropología estructural, para interpretar los mitos de sociedades de oralidad primaria: "cuando los antropólogos exponen sobre una superficie escrita o impresa listas de varios artículos hallados en los mitos orales (tribus, regiones de la tierra, tipos de viento, y así sucesivamente), en realidad deforman el mundo mental en el cual los mitos tienen su existencia propia. La satisfacción que proporcionan los mitos en esencia no es 'coherente' de un modo tabular" (Ong 1987: 101).

En una referencia directa al método de Lévi-Strauss, Ong señala claramente sus carencias, limitaciones y el abismo que existe entre las tradiciones culturales que estudia y su perspectiva teórica: 
La analogía fundamental de Lévi-Strauss para la narración es el lenguaje mismo, con su sistema de elementos constantes: fonema, monema, etcétera. Él y sus muchos seguidores por lo general han prestado poca o ninguna atención a la psicodinámica específica de la expresión oral como es elaborada por Parry, Lord, y particularmente Havelock y Peabody. La referencia a tales obras agregaría otra dimensión al análisis estructuralista, al cual a menudo se acusa de ser demasiado abstracto y tendencioso: todas las estructuras observadas resultan ser binarias (vivimos en la época de la computadora), y lo binario se logra omitiendo los elementos, con frecuencia importantes, que no se ajustan a las pautas binarias. Además, las estructuras binarias, por interesantes que sean las configuraciones abstractas que forman, no parecen explicar la urgencia psicológica de una narración y por lo tanto no logran esclarecer por qué el relato es un relato.

Los estudios de la oralidad como tal han hecho resaltar que la narración oral no siempre se arma según términos que permitan un rápido análisis estructuralista binario, o incluso el rígido análisis temático que Propp (1968) aplica al cuento popular (Ong 1987: 159-160).

Desde esta perspectiva, las categorías y oposiciones lógicas "binarias" empleadas por Lévi-Strauss para interpretar el significado subyacente de los sistemas mitológicos son arbitrarias y reductivas; no son sino una proyección de sus propias preconcepciones sobre los datos observados. Se trata, en repetidas ocasiones, de categorías fijas que se aplican a todos los casos, sin que la pertinencia de las mismas se justifique adecuadamente, sea razonable o, incluso, obedezca al sentido común, incurriendo, así, en lo que describe Heidegger cuando critica el proceder de los métodos apriorísticos, señalando que lo que hacen es forzar al ente a entrar en conceptos en los que se resiste a entrar por su forma de ser (Heidegger 2000). Así, por ejemplo, en un cuadro que aparece en la página 18 de Mitológicas III, Lévi-Strauss, en su afán de continuar empleando sus categorías de crudo y cocido, sitúa a la orina dentro de la categoría de lo crudo y a los excrementos dentro de lo cocido. Un proceder totalmente arbitrario: los argumentos esgrimidos para justificar dicha clasificación no son claros, carecen por completo de coherencia (Lévi-Strauss 1981 [1968]: 18). 


\section{El caso del mito de Edipo}

En el ejemplo que él utiliza en la Antropología estructural, no es posible afirmar que el tema central del mito de Edipo sea el de la oposición entre "la reproducción bisexuada" y "la autoctonía", a partir de meras inferencias lógicas, surgidas del análisis estructural del texto, sin contraste alguno con los datos histórico-culturales concretos que nos permitirían conocer el lugar y el sentido que dichas narrativas jugaban en las vidas de los seres humanos, pertenecientes a las tradiciones que las produjeron y sobre las cuales existe una abundantísima documentación. Veamos la conclusión a la que llega:

¿Qué significaría, pues, el mito de Edipo interpretado así, "a la americana"? Expresaría la imposibilidad en que se encuentra una sociedad que profesa creer en la autoctonía del hombre [...] de pasar de esa teoría al reconocimiento del hecho de que ha nacido realmente de un hombre y de una mujer. La dificultad es insuperable. Pero el mito de Edipo ofrece una suerte de instrumento lógico que permite tender un puente entre el problema inicial - ¿se nace de uno solo o bien de dos? - y el problema derivado que se puede formular aproximadamente así: ¿lo mismo nace de lo mismo, o de lo otro? De esta manera se desprende una correlación: la sobrevaloración del parentesco de sangre es la subvaloración del mismo, como el esfuerzo por escapar de la autoctonía es la imposibilidad de lograrlo. La experiencia puede desmentir la teoría, pero la vida social verifica la cosmología en la medida que una y otra revelan la misma estructura contradictoria (Lévi-Strauss 1970: 196-197).

Me sorprende la conclusión. Tal contradicción nunca existió, realmente, es un mero producto de la especulación racionalista del autor: la conciencia de la autoctonía y el consecuente sentido de pertenencia a una comunidad, propios de la tradición griega antigua, no negaban, ni excluían, ni impedían que existiera la conciencia de la paternidad y la maternidad; por el contrario, se fundaban una en la otra y sólo podrían entrar en contradicción cuando alguien trasgredía las leyes sociales que las sancionaban. Tales son los casos de Edipo, Polinice y Antígona, de ahí que la tragedia consista en el dilema vital que enfrentan aquellos que rompen con la ley y la manera en la cual tal ruptura conduce al desastre. 
De hecho, la fortaleza de la comunidad griega se sostenía sobre la base de la unidad y complementariedad de las instituciones de la familia y de la polis, las cuales se sustentaban mutuamente. Sólo mediante una lectura basada en meras oposiciones lógicas abstractas que dejan de lado el nudo central de la trama y la historicidad del mito, se puede llegar a una conclusión tan absurda como la de Lévi-Strauss. Ni el método, ni el sistema "binario" apriorístico se sostienen, después del análisis crítico posterior. ¿Quién intenta escapar de la autoctonía en el mito de Edipo? Nadie. La autoctonía es un valor incuestionable. ¿Quién está por encima o por debajo del vínculo de sangre? Nadie. El vínculo sanguíneo es incuestionable. Más aún, no necesitamos llevar a cabo un análisis estructural del mito de Edipo para saber que los mitos, en general, posibilitan la conciliación de los contrarios, la coincidentia oppositorum; eso se sabía desde hace mucho tiempo, tal como lo encontramos en la obra de Heráclito y de Nicolás de Cusa por mencionar sólo a dos autores destacados.

En todo caso, de lo que intenta escapar Layo es del destino que le predice el oráculo. Pero el oráculo habla siempre en términos enigmáticos, ambiguos, obliga a una interpretación metafórica que va más allá de sus términos literales, tal como lo afirma Heráclito: "El Señor cuyo oráculo está en Delfos, no dice ni oculta, sino indica por medio de signos" (Heráclito 2011: 65). Layo lo interpreta en un sentido literal y su interpretación lo lleva, en contra de su propia voluntad, a propiciar lo contrario de lo que desea. A causa de ese proceder, el sentido "literal" del oráculo se cumple. El mito de Edipo nos enseña, en primer lugar, a meditar, a indagar, a reflexionar sobre el sentido oculto, presente en el decir del oráculo. Pone de manifiesto la necesidad de una hermenéutica que nos permita descifrar las enigmáticas palabras de los dioses. Nos enseña a no actuar precipitadamente, con base en falsas conjeturas.

Carlos García Gual, experto en mitología griega antigua, critica la interpretación de Lévi-Strauss y, de paso, la de Freud:

Ahora bien, quizás algunos lectores piensen, como C. Lévi-Strauss, que la estructura de un mito permanece invariable a lo largo de sus versiones, aunque en la demostración de esa tesis se incurre en un círculo vicioso. Pero, bueno, dejémoslo como un problema. ¿Es que la trama del mito de 
Edipo, desde la épica a las versiones trágicas, y luego al famoso "complejo" (que desde luego no pudo conocer el héroe del mito, niño expósito y exiliado voluntario), está inalterada en las repetidas evocaciones literarias griegas? ¿Son las variaciones de un mito sólo alteraciones marginales?

En todo caso, queda claro que la literatura antigua se construye sobre el humus fértil de la mitología, y todos los géneros poéticos antiguos (la épica, la lírica coral y la tragedia) fundan en ese substrato sus argumentos. Frente a la tradición mítica se ha construido luego la filosofía, la historia, y las investigaciones científicas, como saberes críticos racionales. Se han creado frente a los mitos, en oposición a ellos, en busca de una nueva explicación, fundada en la razón, no en la tradición (García 1989: 33-35).

Richard Buxton, especialista en religión y literatura griegas, señala en su introducción a El imaginario griego que: "no hay mal que por bien no venga: la certeza con que los estructuralistas y otros han hablado de naturaleza y cultura, de los griegos y del pensamiento griego, ha perdido vigencia en provecho de una saludable toma de conciencia de las diferencias" (Buxton 2000 [1994]: 16). De ahí que proponga la necesidad de interpretar los mitos en su contexto:

No aporto nada a la búsqueda emprendida por algunos del significado supuestamente transhistórico o universal de los mitos, por cuanto entiendo que tal camino no tiene objeto o como mínimo, sus resultados no son verificables. Pero situar las narraciones dentro de las comunidades básicamente campesinas en las que se relataban; analizar los contextos narrativos y los contextos sociales; acotar la distancia que media entre la fantasía narrativa y la vida cotidiana, todo ello me parece tarea útil y, lo que no es menos importante, posible (Buxton 2000: 18).

Es de esta manera que se pone de manifiesto el pluralismo del mito, de sus significados, funciones y contextos. Buxton demuestra que la sociedad griega se caracterizaba por el intercambio de narraciones, entre las cuales, los relatos sobre los orígenes jugaban un papel fundamental y su carácter era eminentemente dialógico y plural: "las ficciones y los contextos sí tuvieron al menos una característica común: la pluralidad de la voz. En la sociedad de la polis arcaica y clásica, en una serie de ámbitos, la narración fue una empresa competitiva" (Buxton 2000: 24). 
Tal carácter provenía de su antigua tradición oral, anterior a la escritura. En referencia a ella, Eric Havelock señala que la literatura griega había sido poética porque la poesía había jugado la función social de preservar la tradición a partir de la cual los griegos vivían y eran instruidos en ella; lo que quería decir que la tradición era enseñada y memorizada oralmente (Havelock 1986: 8). García Gual señala que "es la comunidad entera del pueblo quien guarda y alberga en su memoria esos relatos. Los mitos circulan por doquier. Las instituciones se apoyan en los mitos; se recurre a ellos para tomar decisiones; se interpretan hechos de acuerdo con ellos" (García 1989: 27). Kirk sostiene que: "Los mitos tradicionales eran, a fin de cuentas, el hecho cultural dominante de la vida griega" (Kirk 1992: 92).

La narración mítica estaba presente en la educación de los niños, desde pequeños, en el ámbito doméstico; en la educación de los jóvenes, en un ámbito socialmente sancionado; en celebraciones públicas y privadas de ciudadanos, acompañadas del canto y la recitación y, especialmente en Atenas, adquirió una cualidad relevante en la tragedia (Buxton 2000: 31-53; García 1989: 27-28 y 37), tal como pensadores de la talla de Aristóteles, Hegel, Nietzsche, Heidegger y Gadamer lo han destacado. Especialistas en el tema, como Carlos García Gual, ponen de relieve esta cuestión: "La épica y la tragedia - y también la lírica coral doria - fueron no sólo formas de arte, sino también instituciones sociales con valor educativo" (García 1987: 37).

De acuerdo con Paul Diel, el tema central de los mitos griegos, y en especial de la tragedia, es el de las transformaciones energéticas entre el deseo exaltado y su deseable orientación armónica. La satisfacción armoniosa de los deseos es el sentido último de la vida, su sentido espiritual (Diel 1991 [1966]).

Buxton subraya que a finales del siglo vi a. C., cuando surge la tragedia, ésta significa "una forma de narración mítica sin precedentes en cuanto a la participación de toda la polis"; la tragedia ateniense revela "una ciudad discutidora y obsesionada con la palabra [...] la tragedia formula preguntas molestas" (Buxton 2000: 43); concluye que: "A pesar de su intensa y fantástica exageración, pero también debido a ella, la tragedia demuestra, con fuerza sólo comparable a la de la Ilíada, que los 'simples relatos' pueden despejar zonas de experiencia más 
extrañas y profundas que todas las indagadas por la cultura griega" (Buxton 2000: 25).

Así, resulta que los sucesos presentados por el mito y la tragedia son profundos y trascendentes en términos de la experiencia humana y, por eso, mueven las emociones, cuya catarsis deben provocar. Tragedia y mito tienen el mismo fin: que el hombre pueda conocer el thelos divino que subyace y estructura al cosmos. Por lo cual, dirá Gadamer: "Frente al poder del destino el espectador se reconoce a sí mismo y a su propio ser finito" (Gadamer 1999: 178). Se trata de "una especie de autoconocimiento del espectador, que retorna iluminado del cegamiento en el que vivía como cualquier otro" (Gadamer 1999: 179).

Coincidiendo con autores como Gadamer y Blumenberg, Buxton subraya que no existía una oposición radical entre mythos y logos: "en un nutrido conjunto de pasajes que se remontan incluso al periodo arcaico mythos y logos se emplean sin ninguna de las oposiciones mencionadas" (Buxton 2000: 26). Lo que nos conduce a una descripción de ciertas características fundamentales de la interpretación del mito en la Grecia antigua:

La religión griega no es la religión de la doctrina correcta. No tiene ningún libro sagrado cuya adecuada interpretación fuese el saber de los sacerdotes, y justo por eso lo que hace la ilustración griega, a saber, la crítica del mito, no es ninguna oposición real a la tradición religiosa. Sólo así se comprende que en la gran filosofía ática y, sobre todo, en Platón pudiesen entremezclarse la filosofía y la tradición religiosa (Gadamer 1997 [1981]: 17-18; Pieper 1984 [1965]).

Gadamer concluye que en el contexto de la Grecia clásica no podía hablarse de la "oposición extrema entre mito y logos con que estamos familiarizados" (Gadamer 1997: 26). Hans Blumenberg pone de relieve que, tal como mostraba Nietzsche, los antiguos griegos vivieron sin una teología normativa y todo mundo tenía derecho a inventar y creer en lo que quisiese (Blumenberg 2004 [2001]: 22). Más aún, "La fascinación que ejercía el mito se debía precisamente a que era mera representación, sólo necesitaba ser 'creído’ momentáneamente, pero nunca devino norma o credo" (Blumenberg 2004: 23). El mito, afirma Blumenberg, dominó la fantasía de los antiguos griegos y les produjo un gran placer. 
Aquel pueblo tan excitable en sus sentimientos — dice Nietzsche - , tan impetuoso en sus deseos, tan excepcionalmente capacitado para el sufrimiento, ¿de qué otro modo hubiera podido soportar la existencia, si en sus dioses ésta no se le hubiera mostrado circundada de una aureola superior? El mismo instinto que da vida al arte, como un complemento y una consumación de la existencia destinados a inducir a seguir viviendo, fue el que hizo surgir el mundo olímpico, en el cual la "voluntad" helénica se puso delante de un espejo transfigurador. Viviéndola ellos mismos es como los dioses justifican la vida humana ¡única teodicea satisfactoria! (Nietzsche 1981 [1872]: 53; cursivas en el original).

Reconociendo esta gran apertura en la interpretación de las tradiciones míticas que se da en el mundo griego antiguo, considero inadmisible la pretensión de Lévi-Strauss de cerrar el significado del mito edípico, pues si bien, como Graves (1989 [1955]: 7-15) y Buxton, reconoce que las fuentes del mito de Edipo son muy variadas y las posibles articulaciones y versiones del mismo muy distintas, y aun contradictorias entre sí, además, propone que todas las variantes deben ser tomadas en cuenta por el análisis estructural (Lévi-Strauss 1970), resulta totalmente incongruente no abrirse a la pluralidad semántica del mito y cerrar la interpretación a un significado único, que él mismo sabe que es problemático.

Más aún, las distintas versiones del mito de Edipo se contradicen entre sí, derivando en sucesos y desenlaces distintos al nivel de los diversos mitemas que lo componen (Graves 1989: 12-15). A éstas se agregan las diferencias entre las versiones literarias y las pictóricas (Buxton 2000; Snodgrass, 1998). Graves incluso plantea que es posible que “Oedipus, 'pie hinchado' fuera originalmente Oedipais, 'hijo del mar agitado", pues, según otra versión "Layo no abandonó a Edipo en la montaña, sino que lo encerró en un arca que fue arrojada al mar desde su barca" (Graves 1989: 12 y 8). De modo que, si el problema es complejo, la solución simple resulta banal y artificiosa. La posición de Lévi-Strauss al respecto es totalmente ambigua. Por un lado, señala sobre su interpretación que no se trata de "una explicación aceptable para el especialista", pero, por el otro, cree firmemente en el resultado al que ha llegado, siguiendo al pie de la letra su método.

Cada uno de los problemas que plantea el mito de Edipo son tan complejos que derivan en paradojas. Así, por ejemplo, la relación entre 
el oráculo y el destino plantea una paradoja radical: intentar ir en contra del destino es lo que conduce a su realización. ${ }^{3}$ Resulta, sin embargo, fundamental, aclarar aquí que paradoja no equivale a oposición lógica "binaria", tal como lo han puesto en claro los especialistas en la tragedia. Las paradojas y disyuntivas éticas que enfrentan los personajes de la tragedia sólo se pueden resolver en el campo de la existencia misma, no se resuelven lógicamente, se resuelven vivencialmente, se resuelven en el campo de la existencia temporal, de la diacronía que une e hila, narrativamente: el tiempo original de los mitos, el tiempo vivo del mito y sus recitadores, el tiempo de la tragedia (autores y espectadores) y el tiempo hermenéutico de las sucesivas interpretaciones, al interior de la tradición occidental. Esas sucesivas interpretaciones constituyen la sustancia de la propia historia cultural de Occidente.

Es en tal sentido que García Gual afirma que la mitología griega cuenta con una condición singular: la de presentarnos una tradición que podemos estudiar diacrónicamente (García 1989: 40-41). Esto nos permite llegar a una comprensión de los mitos clásicos, mediante un proceder hermenéutico que los emplaza dentro del despliegue de la tradición grecolatina occidental, entendida como una tradición creada, re-creada e interpretada históricamente, ${ }^{4}$ sigo en esto a Ricoeur.

Aquí, coincidimos con las observaciones de Ricoeur a Lévi-Strauss, cuando opone al ejemplo del totemismo, utilizado por este último para mostrar las bondades del método estructural en El pensamiento salvaje (Lévi-Strauss 1994 [1962]), el ejemplo de la tradición hebrea (Ricoeur 2003: 31-60), para mostrar las bondades de un método cuya primacía se sitúa en la dimensión diacrónica - en ello sigue la extraordinaria exégesis de Gerhard Von Rad del Antiguo Testamento- (Von Rad 2005 [1958]). Ricoeur demuestra que, en este caso particular (tradición hebrea), es posible hablar de "una primacía de la historia" (Ricoeur

3 Para una interpretación detallada, sistemática y profunda de cada uno de los pasajes y, mejor aún, del trasfondo psíquico, moral y espiritual del Edipo, remitimos al lector a la obra referida de Paul Diel, quien además lleva a cabo una crítica seria y cuidadosa de la interpretación freudiana (1991: 143-164). Aquí no nos es posible, no lo consideramos deseable, presentar una síntesis apretada de su proposición que desvirtuaría su significado más amplio y profundo.

$4 \quad$ Para el caso de la tradición clásica en el arte, véase Greenhalgh (1987 [1978]) y Spencer (1975: 357-461). 
2003: 47). "El trabajo teológico sobre estos acontecimientos [bíblicos] es, en efecto, una historia ordenada, una tradición que interpreta. Para cada generación, la reinterpretación del fondo de las tradiciones confiere un carácter histórico a esta comprensión de la historia, y suscita un desarrollo cuya unidad significante es imposible de proyectar en un sistema" (Ricoeur 2003: 47-48). Concluye: "Así se encadenan las tres historicidades: después de la historicidad de los acontecimientos fundadores - o tiempo oculto - y de la historicidad de la interpretación viva por parte de los escritores sagrados — que constituye la tradición-, tenemos ahora la historicidad de la comprensión, la historicidad de la hermenéutica (Ricoeur 2003: 48).

En la tragedia griega nos enfrentamos a disyuntivas existenciales cuya resolución implica una identificación y una toma de posición ética y emotiva por parte del espectador. En la tragedia, la polis cobraba conciencia de sí misma. La polis se expresaba en y por la tragedia. Ahí estaba el lugar de la revelación, donde aparecía la precariedad sobre la cual se levanta la existencia humana, las disyuntivas sobre las cuales se edifica. La tragedia enseñaba a prevenir la űbpıs (hibris), inculcando el cuidado absoluto, la prevención de cualquier desmesura. El ideal griego era el de una vida buena y bella que se permitía disfrutar de los placeres, sin caer en los excesos (hibris).

En la época clásica de la comunidad griega parece no haber existido una distinción tajante entre ontología y axiología, los seres humanos estaban inmersos en la sustancia ética: pertenecer a la comunidad significaba ser como se tiene que ser. Ser ateniense significaba vivir de acuerdo con las normas del saber vivir, de acuerdo con el arte total que era la vida buena y bella. El ethos griego era lo que dotaba de sentido a la existencia de los miembros de la comunidad, era la sustancia de su propio existir: era inconcebible vivir de otra manera. Eso es lo que entiendo cuando me refiero al concepto hegeliano de sustancia ética. ${ }^{5}$

Hegel define la sustancia ética de la siguiente manera: el espíritu es la realidad ética. Es el sí mismo de la conciencia real a la que se enfrenta, o que más bien se enfrenta a sí misma, como mundo real objetivo, el cual, sin embargo, ha perdido para el sí mismo toda significación de algo extraño, del mismo modo que el sí mismo ha perdido toda significación de un ser para sí, separado, dependiente o independiente, de aquel mundo. El espíritu es la sustancia y la esencia universal, igual a sí misma y permanente - el inconmovible e irreducible fundamento y pun- 
El vivir sólo se concebía como formar parte de la familia y de la polis. Fuera de la familia y de la polis no era posible existir. Por eso los castigos más terribles eran el destierro o el repudio familiar, equivalían a la pena de muerte. Inmersa en la sustancia ética, la tragedia era un modo de vida, no un género literario.

Las disyuntivas éticas que plantea la tragedia pueden ilustrarse a partir de la interpretación hegeliana de la tragedia de Antígona, no importa que se pueda diferir de su interpretación (Hegel 1973: 254, 279-283). Hegel sostiene que la "autoconciencia ética forma unidad inmediata con la esencia por medio de la universalidad de su Sí mismo”. Dicha conciencia que se ha superado como singular "es autoconciencia de la sustancia ética". La autoconsciencia es "un comportamiento simple y claro" (Hegel 1973: 254; cursivas en el original). Las leyes sobre las que se asienta la sustancia ética: "Son y nada más: esto es lo que constituye la conciencia de su relación. Por eso estas leyes valen para la Antígona de Sófocles como el derecho no escrito e infalible de los dioses" (Hegel 1973: 254; cursivas en el original).

Kirk afirma que: "El método de plantear y examinar problemas actuales a través de una situación mítica tradicional se hace todavía más patente en la Antígona de Sófocles, escenificada en el año de 411 a. C., cuando la naturaleza de la ley y los deberes que el Estado le impone se discutían entre políticos y filósofos" (Kirk 1992: 86). Confrontando tal reflexión con el relato de la tragedia, podemos inferir que el modo de vida presente en la Antígona se asentaba en dos leyes complementarias, que sólo entraban en contradicción cuando se las trasgredía, cuando los personajes trágicos cometían una falta grave. Hegel afirmaba haber descubierto su unidad y oposición complementaria en la Antígona de Sófocles. Esas dos leyes eran igualmente fuertes y su obligatoriedad,

to de partida del obrar de todos - y su fin y su meta, como el en sí pensado de toda autonomía. Esta sustancia es, asimismo, la obra universal, que se engendra como su unidad e igualdad mediante el obrar de todos y de cada uno, pues es el ser para sí, el sí mismo, el obrar. Como la sustancia, el espíritu es la inmutable y justa igualdad consigo mismo; pero, como ser para sí, es la esencia que se ha disuelto, la esencia bondadosa que se sacrifica en la que cada cual lleva a cabo su propia obra, que desgarra el ser universal y toma de él su parte. Esta disolución y singularización de la esencia es cabalmente el momento del obrar y el sí mismo de todos; es el movimiento y el alma de la sustancia y la esencia universal efectuada (Hegel 1973: 259-260; cursivas en el original). 
imperativa: la ley clara o masculina y estatal, representada por los varo-

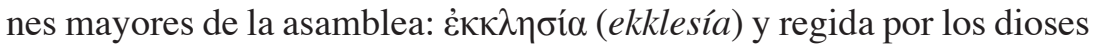
diurnos olímpicos; la ley oscura o femenina y familiar, ley de la sangre, basada en la estructura reproductiva básica, regida por los dioses del mundo inferior.

A partir de lo anterior descubrimos que el tema de la autoctonía, más que ser un asunto fundante en la tragedia de Edipo Rey, tal como lo afirma Lévi-Strauss, está presente de manera más patente en la tragedia de Antígona. El asunto central del Edipo no gira en torno al arraigo o desarraigo respecto de su comunidad (autoctonía), sino en torno a su desarraigo personal (psíquico y moral), de manera que Edipo: "Suple su inferioridad (alma herida) por la activa búsqueda de la superioridad dominante. Ambiciona el poder sobre los demás, el reino sobre el país, sobre el mundo, y así se transforma en rey activo. Pero su éxito exterior será la causa de su fracaso interior, según la ambigua predicción del oráculo" (Diel 1991: 145).

Volviendo a la tragedia de Antígona, la lucha por el poder entre Polinices y Eteocles, hermanos y herederos del trono, quienes deben turnarse anualmente en el poder, se suscita debido a que este último no está dispuesto a cederle temporalmente a aquél el reino, por lo cual Polinices se rebela, obteniendo ayuda extranjera. $\mathrm{Al}$ respecto dirá Hegel:

Vista la cosa de un modo humano, ha delinquido quien, privado de posesión, ataca a la comunidad al frente de la cual se hallaba el otro; y, por el contrario, tiene a su lado el derecho el que ha sabido considerar al otro solamente como singular [...] La comunidad honrará a quien estuvo a su lado; en cambio, el gobierno, que es la simplicidad restaurada del sí mismo de la comunidad, castigará, privándolo de los últimos honores, al otro, al que ya sobre los muros pronunció su destrucción; quien ha venido a atentar contra el supremo espíritu de la conciencia, el de la comunidad (Hegel 1973: 279280; cursivas en el original).

Polinices, en busca de recuperar el poder que considera le pertenece legítimamente, se rebela contra su comunidad, gobernada por su hermano Eteocles, para lo cual recurre a la ayuda extranjera. Muere en la batalla y es condenado a permanecer insepulto. Es ahí donde la ley clara y la ley oscura entran en contradicción, debido a la trasgresión 
de Polinices. El desgarramiento del ser humano trágico, que se rige por esta doble ley, es el que, según Hegel, se muestra en la tragedia de Antígona, quien ha decidido desobedecer la ley clara para cumplir con la oscura. Desobedece para poder sepultar a su hermano Polinices, quien, como vimos, ha sido castigado con la pena de permanecer insepulto a causa de haber luchado en contra de su ciudad. La ley clara dice que a quien defienda a su ciudad se le protegerá y a quien la combata se le castigará. Polinices se ha rebelado en contra de ella y ha muerto en la batalla, debe, así, permanecer insepulto y ser devorado por las fieras y aves de rapiña.

Este es un castigo terrible que Antígona no puede permitir que caiga sobre su hermano y decide contradecir a Creonte y desafiar la pena de lapidación a la que se condena a quien viole la ley, para cumplir con la exigencia más primaria y esencial, para ella, de la ley de la sangre y de la prescripción del rito religioso, por lo cual decide sepultar a su hermano. El conflicto central de la tragedia de Antígona radica en la oposición de estas dos leyes, vivida por el personaje principal, que encarna esta disyuntiva moral y existencial. Haga lo que haga será culpable porque su situación la hará desobedecer a alguna de las dos leyes. Una, la ley del Estado, el derecho; la otra, la ley de la sangre, la ley religiosa. Como queda claro, se trata de un conflicto existencial que se resuelve en una decisión vital y no un problema lógico de oposiciones "binarias" que se pueda definir en un esquema analítico.

\section{Conclusiones}

Desde esta perspectiva, la metodología interpretativa empleada por LéviStrauss para abordar el mito de Edipo puede caracterizarse con el término que Durand emplea: hermenéutica reductiva, en tanto reduce la problemática de todo sistema mitológico $\mathrm{y}$, por consecuencia, de toda disyuntiva vital humana, a meras oposiciones "binarias" de estructuras lógicas racionales.

Al respecto quiero subrayar, en primer lugar, que los relatos mitológicos son complejos y su estructura es plural y no "binaria", como él pretendía. Al interior de cada sistema mitológico, las agrupaciones y 
oposiciones de personajes, acciones y conceptos varían, no es siempre dual -lo cual no equivale a binario-, ni el criterio dual se puede aplicar a todos los aspectos de una mitología. Un análisis serio y sistemático de las narrativas mitológicas de cualquier grupo cultural pondrá en evidencia que su lógica interna va más allá de las meras oposiciones duales: mostrará que los pasajes míticos que se rigen a partir de oposiciones duales son sólo una parte del conjunto mitológico, y que tal lógica no se puede ni debe aplicar a todo el conjunto de un sistema mítico. De ahí que la pretensión de reducir de manera indistinta todo sistema mitológico a oposiciones "binarias" es un proceder del todo arbitrario y artificioso: un a priori del método, no verificable de manera sistemática en el análisis concreto. Incluso, en los mitos narrados en Mitológicas encontramos que son las articulaciones múltiples y variables las que mueven las acciones y conflictos de y entre los personajes, los seres y las cosas, y no las meras oposiciones "binarias".

En el modelo analítico estructuralista el sistema "binario" constituye un a priori de la investigación, podemos criticarlo, precisamente, por su total exterioridad, respecto del asunto estudiado; Lévi-Strauss llega a sus conclusiones a través de la extrema formalización y matematización del significado. Así, incurre en el procedimiento característico de los reduccionismos racionalistas que, tal como lo ha demostrado Gilbert Durand: "sólo descubren la imaginación simbólica para tratar de integrarla en la sistemática intelectualista en boga y reducir la simbolización a un simbolizado sin misterio" (Durand 1971: 47). Más aún, "semejante método de reducción a las 'evidencias' analíticas se presenta como el método universal [...] El símbolo - cuyo significante ya no tiene más que la diafanidad del signo - se esfuma poco a poco en la pura semiología, se evapora, podríamos decir, metódicamente en signo" (Durand 1971: 27). De tal forma, la "reducción del ser a un tejido de relaciones objetivas, [ha] eliminado en el significante todo lo que era sentido figurado, toda reconducción hacia la profundidad vital del llamado ontológico" (Durand 1971: 29).

En referencia al método de Lévi-Strauss, Clifford Geertz afirma: "Disponer cristales simétricos de significación, purificados de la complejidad material en que estaban situados, y luego atribuir su existencia a principios autógenos de orden, a propiedades universales del espíritu 
humano o a vastas Weltanschaungen a priori, es aspirar a una ciencia que no existe e imaginar una realidad que no podrá encontrarse" (Geertz 1997: 32). Aún antes de la aparición del estructuralismo (1944), Ernst Cassirer había ya manifestado un punto de vista crítico, respecto de las interpretaciones racionalistas del mito:

De todos modos, una teoría del mito se presenta, desde un principio, cargada de grandes dificultades. El mito, en su verdadero sentido y esencia, no es teórico; desafía nuestras categorías fundamentales del pensamiento. Su lógica, si tiene alguna, es inconmensurable con todas nuestras concepciones de la verdad empírica o científica; pero la filosofía no pudo admitir jamás semejante bifurcación. Estaba convencida de que las creaciones de la función mitopoyética debían de tener un "sentido" filosófico, inteligible [...] No necesitamos examinar en detalle estas teorías; por mucho que difieran de contenido nos revelan todas la misma actitud metódica. Pretenden hacernos comprender el mundo mítico por un proceso de reducción intelectual; pero ninguna de ellas puede lograr su fin sin constreñir y mutilar constantemente los hechos al efecto de convertir la teoría en un todo homogéneo (Cassirer 1997: 115-117).

Sobre el método estructural, concluye Durand: "se ha reducido a un modelo subjetivo único, y por ello hipostasiado en objetividad, lo que, en sí, tiene como función expresar una expresividad múltiple” (Durand, 1993: 41).

Vale la pena, sin embargo, dejar en claro un asunto importante para la hermenéutica del mito, si bien discrepo de la manera en la cual Lévi-Strauss plantea el problema de la estructura de los mitos, considero que sería absurdo sostener que los mitos no tienen una estructura definida y que tales estructuras, que denomino patrones míticos, no se puedan identificar. Sostengo, no obstante, que el análisis de su estructura debe de hacerse de otra manera (Amador 2004, 2008), cuestión que no me es posible exponer aquí en detalle. Aquí, sólo puedo esbozar sus lineamientos generales: los patrones míticos implican estructuras ordenadas que articulan sus distintos aspectos constitutivos: $a$ ) estructura formal: secuencias de relaciones de los elementos lingüísticos, sintáctica y estéticamente ordenados; $b$ ) estructura simbólica: secuencias que regulan las relaciones de los símbolos entre sí, al interior de los cambiantes campos 
semánticos del relato; c) estructura de la narración: secuencias de relaciones de los personajes con las acciones, los sucesos y las situaciones; d) estructura de los contenidos y su lógica argumental: secuencias de relaciones de los temas entre sí, y e) estructura del código cultural. Las funciones de los anteriores cuatro tipos de secuencias, constituyen los medios específicos de expresión de los códigos culturales fundamentales, los cuales dotan de sentido a la mitología y a la cultura como un todo. Destacan, de esta manera, las estructuras estéticas, sintácticas, lógicas, semánticas, simbólicas y temáticas de los mitos, que sólo pueden comprenderse, de manera concreta, al ser confrontadas con su contexto práctico específico, a partir de los materiales etnohistóricos y etnográficos. Situar a los mitos en su contexto implica definir sus $d i$ mensiones prácticas, implica situarlos en su mundo de vida. Más aún, implica recuperar para la antropología al ser humano vivo, desterrado por los estructuralismos. Todo esto nos lleva a enunciar el problema de la lógica específica de los mitos. Pues los patrones míticos cobran sentido al interior de una lógica discursiva que es propia de cada relato mítico y de cada tradición cultural.

\section{Bibliografía}

AmAdor Bech, Julio (2004). Las raíces mitológicas del imaginario político. México, Universidad Nacional Autónoma de México/Miguel Ángel Porrúa.

- (2008). El significado de la obra de arte. Conceptos básicos para la interpretación de las artes visuales. México, Universidad Nacional Autónoma de México.

BARTHES, Roland (1980). Mitologías. México, Siglo XXI Editores.

Blumenberg, Hans (2004). El mito y el concepto de realidad. Barcelona, Herder.

Buxton, Richard (2000). El imaginario griego. Los contextos de la mitología. Cambridge, Cambridge University Press.

CAssirer, Ernst (1997). Antropología filosófica. México, Fondo de Cultura Económica.

Diel, Paul (1991). El simbolismo en la mitología griega. Barcelona, Labor.

DurAnd, Gilbert (1971). La imaginación simbólica. Buenos Aires, Amorrortu.

- (1993). De la mitocrítica al mitoanálisis, Figuras míticas y aspectos de la obra. Barcelona, Anthropos/Universidad Autónoma Metropolitana. 
GADAMER, Hans-Georg (1997). Mito y razón. Barcelona, Paidós.

- (1999). Verdad y método. Salamanca, Sígueme.

García Gual, Carlos (1989). La mitología. Interpretaciones del pensamiento mítico. Barcelona, Montesinos.

GeERTz, Clifford (1997). La interpretación de las culturas. Barcelona, Gedisa.

Graves, Robert (1989). Los mitos griegos, 2. México, Alianza Editorial Mexicana.

Greenhalgh, Michael (1987). La tradición clásica en el arte. Madrid, Hermann Blume.

HaVELock, Eric (1986). The Muse Learns to Write: Reflections on Orality and Literacy from Antiquity to the Present. New Haven y Londres, Yale University Press.

- (1998). "La ecuación oral-escrito: una fórmula para la mentalidad moderna”, en David R. Olson y Nancy Torrance (comps.), Cultura escrita y oralidad. Barcelona, Gedisa.

Hegel, Georg Wilhelm Friedrich (1973). Fenomenología del espíritu. México, Fondo de Cultura Económica.

Heidegger, Martin (2000). Ontología. Hermenéutica de la facticidad. Madrid, Alianza Editorial.

Heráclito (2011). Los límites del alma. Fragmentos. Madrid, Gredos.

KIRK, Geoffrey S. (1992). La naturaleza de los mitos griegos. Barcelona, Labor.

Lévi-Strauss, Claude (1970). Antropología estructural. La Habana, Instituto del Libro, Editorial de Ciencias Sociales.

- (1981). El origen de las maneras de mesa. Mitológicas III. México, Siglo XXI Editores.

- (1985). Las estructuras elementales del parentesco. México, Origen/Planeta.

- (1994). El pensamiento salvaje. México, Fondo de Cultura Económica.

- (1996). Mitológicas I. Lo crudo y lo cocido. México, Fondo de Cultura Económica.

MaLinowski, Bronislaw (1994). Magia, ciencia y religión. Barcelona, Planeta-Agostini.

MAYr, Franz K. (1994). "Hermenéutica del lenguaje y aplicación simbólica”, en K. Kerenyi, E. Neumann, G. Scholem y J. Hillman, Arquetipos y símbolos colectivos, Círculo Eranos I. Barcelona, Anthropos.

NiETzsche, Friedrich (1981). El nacimiento de la tragedia. Madrid, Alianza Editorial.

ONG, Walter (1987). Oralidad y escritura. Tecnologías de la palabra. México, Fondo de Cultura Económica. 
PiePer, Josef (1984). Sobre los mitos platónicos. Barcelona, Herder.

Ricoeur, Paul (1999). Historia y narratividad. Barcelona, Paidós/ICE-UAB.

- (2003). El conflicto de las interpretaciones. Ensayos de hermenéutica. Buenos Aires, Fondo de Cultura Económica.

- (2006). Teoría de la interpretación. Discurso y excedente de sentido. México, Siglo XXI Editores/Universidad Iberoamericana.

- (2007). Tiempo y narración I, Configuración del tiempo en el relato histórico. México, Siglo XXI Editores.

Saussure, Ferdinand de (1979). Curso de lingüística general. Buenos Aires, Losada.

Snodgrass, Anthony (1998). Homer and the Artists. Text and Picture in Early Greek Art. Cambridge, Cambridge University Press.

SPENCER, Harold (1975). "The Classical Tradition in Western Art”, en The Image Maker. Man and his Art. Nueva York, Charles Scribner and Sons.

Von RaD, Gerhard (2005). From Genesis to Chronicles. Explorations in Old Testament Theology. Minneapolis, Fortress Press. 